\title{
Increased duration of extreme thermal events negatively affects cold acclimation ability in a high-latitude, freshwater ectotherm (Ischnura elegans; Odonata: Coenagrionidae)
}

\author{
Lesley A. SMith and Lesley T. LANCASTER \\ Institute of Biological and Environmental Sciences, The University of Aberdeen, Zoology Building Tillydrone Ave, Aberdeen, \\ AB24 2TZ, UK; e-mails: lesley.smith.13@aberdeen.ac.uk, lesleylancaster@abdn.ac.uk
}

Key words. Odonata, Coenagrionidae, Ischnura elegans, damselflies, climate change, thermal niche variability, thermal tolerance, acclimation

\begin{abstract}
Instances of heat waves and cold snaps are becoming more frequent and of increasing duration worldwide. It is well established that short exposure to high or low-temperatures, such as during extreme weather events, often results in adaptive (acclimation/hardening) or maladaptive plastic changes in tolerance of organisms to subsequent thermal stressors. However, little information is available about how the duration of a prior stressful thermal event mediates future organismal thermal responses. Understanding durational effects of thermal conditioning can help predict ectothermic survival in response to novel extreme weather patterns.

We assessed the effect of stressful temperature duration on tolerance to subsequent cold exposure in a widespread freshwater invertebrate species in Britain. Following a week-long acclimation period at $15^{\circ} \mathrm{C}$, wild-caught blue-tailed damselfly Ischnura elegans larvae were held at stressful thermal extreme $\left(2^{\circ} \mathrm{C}\right.$ or $\left.30^{\circ} \mathrm{C}\right)$ temperatures for varying durations designed to mimic a range of extreme to plausible durations of heat waves or cold snaps in the wild (30 min, $2 \mathrm{~h}$, or $24 \mathrm{~h}$ ). After a period of re-equilibration to ambient temperatures $\left(15^{\circ} \mathrm{C}\right)$, we then experimentally assessed CTmin, the temperature which renders an individual unresponsive, as an index of cold tolerance.

Prior exposure to $2^{\circ} \mathrm{C}$, simulating a cold snap, improved future cold tolerance, but only when individuals experienced very brief prior exposures to these conditions ( $30 \mathrm{~min}$ up to $2 \mathrm{~h}$ ), and this benefit was lost following $24 \mathrm{~h}$ prior exposure. Prior exposure to $30^{\circ} \mathrm{C}$, simulating a heat wave, consistently worsened the subsequent cold tolerance of individuals, with the detrimental effect of prior heat exposure increasing linearly as a function of duration.

The research indicates that cold snaps can provide beneficial hardening effects against future cold exposures, but only when these (priming) extreme weather events are of very short duration (here, $30 \mathrm{~min}$ or $2 \mathrm{~h}$ ). Longer durations of exposure to either extreme heat or cold weather events can reduce the ability of individuals to beneficially react to subsequent cold stresses, and may have deleterious effects on future thermal tolerance. The results suggest that increasing durations of extreme temperature events will reduce cold hardening ability of freshwater invertebrates, and that the duration of extreme weather events, or durational changes in freshwater thermal regimes resulting from changes in snowmelt dynamics, is an important parameter to consider when studying organismal responses to climate change.
\end{abstract}

\section{INTRODUCTION}

\section{Duration of extreme weather events}

Irregular bouts of temperature fluctuation occur in marine, freshwater and terrestrial biomes alike (Parmesan, 2006). Global terrestrial climatic temperatures are increasing; as are instances of extreme spells of temperature fluctuation known as cold snaps and heat waves (EASAC, 2013). An increasing area of the globe was affected by increases in extreme climactic events starting in the late 20th century (Frich et al., 2002), and these increasing durations of extreme weather events have been linked to increased concentrations of atmospheric $\mathrm{CO}_{2}$ (Baker et al., 2018). Instances of heat waves will likely continue to become more acute, lengthy and increase in frequency (Kendon et al., 2018) due to the projected increase of mean global temperatures (Meehl \& Tebaldi, 2004).

In temperate regions that typically experience nocturnal relief from high temperature extremes, heat waves lasting $24 \mathrm{~h}$ or more are becoming increasingly more common: In the UK, for instance, there were 2 nights in 2018 which exceeded $20^{\circ} \mathrm{C}$ over a $24 \mathrm{~h}$ period, in comparison to 4 such nights total over the previous 10 years, and only 8 total such nights between 1961-1990 (Met Office, 2018; Kendon et al., 2018; McGrath, 2018). Furthermore, IPCC AR4 climate models suggest that cold snaps will continue to persist despite a warming climate, and in some instances 
cold snap conditions will become more severe (Kodra et al., 2011). In Scotland, where this study was conducted, cold spells have consistently increased in duration over the past 60 years, from an average of 2.1-2.2 days per year in 1961-1990 to 3.4-4.6 days per year in 2008-2017 (Kendon et al., 2018).

Changes in snowpack and runoff dynamics under climate change can also lead to changes in the durations of extreme heat and cold environmental temperature exposures to freshwater ecosystems at high latitudes and elevations. Thus, it is now timely to understand how changing durations of climate extremes affect organismal responses, as a high priority for climate change ecologists. To explain how species will persist despite global warming, it is important to understand the responses of wild individuals, populations, and communities to the different aspects of these temperature perturbations (Deutsch et al., 2008; Gilman et al., 2010; Sgro et al., 2016).

To survive under variable thermal conditions typical of most temperate climate regimes, ectotherms often exhibit adaptive plasticity which allows them to anticipate changing thermal conditions within their lifespan (Sgro et al., 2016; Abram et al., 2017; Manenti et al., 2017). There are two distinct mechanisms of adaptive thermal plasticity in response to cold weather events that afford an organism protection in subsequent otherwise lethal conditions. A rapid cold hardening effect $(\mathrm{RCH})$ is a phenomenon whereby increased survival probability at an otherwise lethal cold temperature follows a short period of exposure to extremely low temperatures (Lee et al., 1987; Chanthy et al., 2012; Sgro et al., 2016). In contrast, cold acclimation is a process believed to be distinct from $\mathrm{RCH}$, and instead results from a longer-term prior exposure to moderately stressful environments which improves survival and performance over longer time frames of days or even weeks (Colinet \& Hoffmann, 2012; Nyamukondiwa et al., 2018).

A number of molecular mechanisms have been implicated in acclimation and cold hardening processes, including production of heat shock proteins (Sørensen et al., 2003; Stoks \& De Block, 2011), mucins, epigenetic regulation, detoxification and proteins involved in ion and water homeostasis (Lancaster et al., 2016; Enriquez \& Colinet, 2019), and other transcriptome- and metabolome-wide changes (MacMillan et al., 2016) which are often highly labile within species (Lancaster et al., 2016).

Although the mechanisms which drive long-term acclimation vs. rapid cold hardening are not completely understood, studies have shown that these mechanisms may be physiologically independent of one another and may even be antagonistic (Rajamohan \& Sinclair, 2009). Moreover, exposure to one extreme temperature (heat or cold) may also confer protective benefits or maladaptive consequences following exposure to the other extreme (Burton et al., 1988, Gotcha et al., 2018). Finally, exposure to stressful temperatures, especially over long durations, may weaken the ability of individuals to respond adaptively, resulting in maladaptive effects of prior thermal exposure at long ex- posure times or when experienced out of context (Buckley \& Huey, 2016).

Previous studies have often investigated how the duration of extreme thermal events affects fitness (Rako \& Hoffmann, 2006; Colinet et al., 2010; Semsar-Kazerouni \& Verberk, 2018), how rearing temperatures interact with starting conditions to affect thermal tolerance (Marais et al., 2009; Nyamukondiwa \& Terblanche, 2010), how repeated exposures to extreme heat or cold affect thermal tolerance, or how the duration of exposure affects survival (Macdonald et al., 2004; Knapp et al., 2018).

Despite an appreciation that physiological mechanisms of thermal hardening, maladaptive plasticity, and acclimation processes differ from each other, and that therefore long vs. short exposures to thermal extremes may have different subsequent effects on thermal tolerance, little has been done to directly investigate how the duration of previous exposure to a stressful or priming thermal event affects the capacity of an organism to respond to a subsequent thermal challenge, after a period of recovery (Waagner et al., 2013; Alemu et al., 2017).

\section{Aims and experimental design}

The aim of this research was to understand how the duration of an extreme temperature bout affects the capacity of individuals to withstand a future bout of thermal stress, via either adaptive hardening or maladaptive physiological plasticity. We tested the hypothesis that as duration of exposure to cold temperatures increased, so too would the hardening response (i.e., ability to withstand a subsequent bout of cold). We further anticipated that short exposures to cold temperatures may produce different levels of future cold protection than longer durations of exposure, with longer durations of prior exposure potentially invoking more maladaptive responses to subsequent stressors than shorter-term prior exposures to the same priming temperature (Knapp et al., 2018). We furthermore questioned whether hardening responses could be achieved in as little as $30 \mathrm{~min}$ of exposure (Lee et al., 1987). Finally, we examined whether exposure to heat stress would provide a protective cold-tolerance response, and if this too depended on the duration of exposure.

\section{Study system}

Zygoptera ("damselflies") are a suborder of Odonata which are known to have substantial phenotypic and ecological diversity, making them excellent study subjects for linking ecology, genomic and evolutionary research (Córdoba-Aguilar, 2008; Bybee et al., 2016). Blue-tailed damselflies (Ischnura elegans Vander Linden, 1820) are ubiquitous across Eurasia and are characteristic of mesotrophic to eutrophic permanent wetlands (Bouton et al., 2011). Climate plays a strong role in the distribution of I. elegans (Lancaster et al., 2015; Sánchez-Guillén et al., 2016; Fitt \& Lancaster, 2017), and this species has been undergoing a rapid range shift in response to climate change (Hickling et al., 2006).

The recent range shift has affected changes in thermal tolerance of this species, with the result that cold tolerance 
phenotypes have improved and gained in adaptive plasticity in cold stress towards the range edge (Lancaster et al., 2015, 2016, 2017a; Wood et al., 2019), and changes in HSP allele frequencies have also shifted towards the range edge in response to temperature gradients (Dudaniec et al., 2018). Understanding how this well-studied species responds to changes in the duration of stressful thermal priming events, in terms of adaptive or maladaptive adjustments to its acclimation capacity, will help develop spatiotemporal estimations for shifts in thermal tolerance and distributional shifts in this and other species (SánchezGuillén et al., 2016; Fitt et al., 2019), when taking changes in the duration of different extreme weather events into account.

\section{METHODS}

\section{Experimental protocol}

Larval I. elegans were collected from a series of ponds at

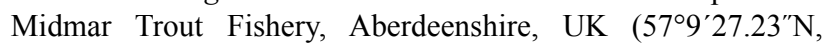
$2^{\circ} 30^{\prime} 10.63^{\prime \prime} \mathrm{W}$ ) during April-June 2018 using fine mesh nets and transported to the laboratory in individual containers filled with pond water. Once returned to the laboratory, each damselfly was identified to species using (Cham, 2009). Head width in millimetres (precision to the nearest $0.01 \mathrm{~mm}$ ) was measured using a Yenway dissecting microscope (YenCam5/ISH500, China) and Yencam associated image software, following Fitt \& Lancaster (2017), as head width is a good proxy for body size in this species. Head width was not positively correlated with capture date (cor $=-0.04$, Kendall $\tau=-0.06, \mathrm{z}=-1.26, P=0.21$ ). Each larva was given a unique identification number. Damselflies were then acclimated at $15^{\circ} \mathrm{C}$ for $7-9$ days. During this period the larvae were fed daily ad libitum with Artemia spp. and Tubifex tubifex. Because damselfly larvae are cannibalistic, they were kept individually in plastic containers (diameter of $6.5 \mathrm{~cm}$ and a height of $3 \mathrm{~cm}$ ) with a piece of artificial pondweed as a perch.

\section{Application of thermal stress}

Each damselfly was allocated a treatment of either $2^{\circ} \mathrm{C}$ (nonlethal stressful cold temperature typically experienced by wild populations during cold snaps that can occur under winter and early spring conditions; Krokowski, 2007), $15^{\circ} \mathrm{C}$ (average spring pond temperature, assessed using $\mathrm{HOBO}$ onset pendant thermal data loggers; Bourne, MA, USA) or $30^{\circ} \mathrm{C}$ (temperature equal to that a wild population might experience in heat wave conditions; Jackson et al., 2018) for a duration of zero hours (i.e., controls retained at $15^{\circ} \mathrm{C}$ ), $30 \mathrm{~min}, 2 \mathrm{~h}$, or $24 \mathrm{~h}$. Size distributions of larvae were kept consistent across treatments (Table 1). After being held at their designated acclimation temperature for the designated duration, individuals were then returned to $15^{\circ} \mathrm{C}$ for a minimum of 2 $\mathrm{h}$ and a maximum of $3.5 \mathrm{~h}$ prior to assessing CTmin (see below). This allowed individuals from both the $0.5 \mathrm{~h}$ exposure time and the $2 \mathrm{~h}$ exposure times to re-acclimate before commencing thermal trials. There was no difference in resulting thermal tolerance between the $0.5 \mathrm{~h}$ and $2.0 \mathrm{~h}$ exposure durations (Table S1, Fig. $\mathrm{S} 1)$, confirming that variation in the reacclimation time did not affect results. This $2 \mathrm{~h}$ re-acclimation at $15^{\circ} \mathrm{C}$ ensures that we are testing the effect of prior thermal exposure on acclimation status, as decoupled from effects of starting conditions, which can confound estimates of the acclimation response (Terblanche et al., 2007). While a rapid transition from $15^{\circ} \mathrm{C}$ to $2^{\circ} \mathrm{C}$ is unlikely to occur in freshwater bodies in nature within $30 \mathrm{~min}$, this extreme example was used to reveal short term, measurable changes in CTmin in response to a brief cold snap.

\section{Thermal tolerance}

Knockdown temperature was chosen as the metric to establish approximate critical thermal minima (CTmin). CTmin is the temperature at which an individual cannot be deemed as functionally responsive and would therefore be unable to react to threats such as predation or make use of resources to feed (Terblanche et al., 2007). Cold tolerance trials were carried out on individuals using a temperature-controlled water bath (Grant-TX150, Cambridge, UK). Each larva was placed into an individually-labelled $50 \mathrm{ml}$ test tube with $27 \mathrm{ml}$ of sieved pond water (to remove substrate) and suspended in the water bath, which was itself filled with a mixture of water and propylene glycol to prevent freezing. A maximum of 25 and minimum of 18 larvae were tested for CTmin per trial. The water bath program commenced at $15^{\circ} \mathrm{C}$ and reduced temperature at a rate of $0.1^{\circ} \mathrm{C}$ per minute. An external temperature probe, which was connected to the water bath thermostat, was inserted into a control $50 \mathrm{ml}$ test tube to ensure that the cooling within the individual test tubes proceeded at the programmed rate. Once the bath temperature reached $11^{\circ} \mathrm{C}$ the larvae were observed constantly, and individuals were gently prodded every minute once activity ceased, to assess knock-down temperature. This was characterised when larvae exhibited loss of muscle coordination and could no longer respond to prodding. Once this unresponsive state was reached, the temperature (CTmin) was recorded and the test-tube containing the individual was then removed from the water bath. A total of 10 cold tolerance trials were run on 222 individual larvae between the $25^{\text {th }}$ of April and the $16^{\text {th }}$ of June.

\section{Statistical methods}

All linear regression analyses were performed using linear models in $\mathrm{R}$ version 3.4 ( $\mathrm{R}$ Core Team, 2017). CTmin was used as the response variable throughout, with fixed, explanatory effects of head width (continuous), temperature (factor)*duration of exposure (continuous) or temperature*duration ${ }^{\wedge} 2$ (modelled as an orthogonal polynomial using the poly $(\mathrm{x}, 2)$ function in R (Kennedy Jr \& Gentle, 1980; Zuur et al., 2010), and the day of year (continuous) on which the damselflies were captured (to account for seasonal effects on cold tolerance). For statistical analysis, individuals retained at $15^{\circ} \mathrm{C}$ were assigned a duration of $0 \mathrm{~min}$ for the test temperature $\left(2^{\circ} \mathrm{C}\right.$ or $\left.30^{\circ} \mathrm{C}\right)$ run on the same day $\left(2^{\circ} \mathrm{C}\right.$ and $30^{\circ} \mathrm{C}$ treatments were run on different days, always accompanied by controls). To identify the best model, the corrected Akaike Information Criterion was used to compare the full model to reduced models (Burnham \& Anderson, 2002; Mazerolle, 2016; Fitt \& Lancaster, 2017). We $\log (\mathrm{n}+1)$ transformed the duration values to conform to the assumptions of the parametric test. Due to the inability of individuals to survive below 0 degrees, CTmin values were modelled using a Gamma general linear model with an identity link function. Variance inflation factors were calculated using the vif() function in the car package for R (Fox \& Weisberg, 2018), and were all found to be $<2$. For plotting, significant marginal quadratic or linear effects of duration were depicted separately for $2^{\circ} \mathrm{C}$ or $30^{\circ} \mathrm{C}$ prior treatment temperature. We further modelled duration of exposure as a factor, and supplementary results are presented in the S.I.

\section{RESULTS}

\section{Effect of acclimation temperature on subsequent thermal tolerance}

CTmin varied between 1.5 and $9.1^{\circ} \mathrm{C}$ across treatments (Table 1). CTmin was best explained by head width, day of year, temperature, duration of exposure, and an interactive effect of temperature $x$ duration and temperature $x$ 
Table 1. CTmin descriptive statistics for all treatments $\left({ }^{\circ} \mathrm{C}\right)$.

\begin{tabular}{|c|c|c|c|c|c|c|c|}
\hline Duration & $0.5(h)$ & $2(h)$ & $24(\mathrm{~h})$ & $0.5(\mathrm{~h})$ & $2(h)$ & $24(\mathrm{~h})$ & - \\
\hline Temperature & $2^{\circ} \mathrm{C}$ & $2^{\circ} \mathrm{C}$ & $2^{\circ} \mathrm{C}$ & $30^{\circ} \mathrm{C}$ & $30^{\circ} \mathrm{C}$ & $30^{\circ} \mathrm{C}$ & $15^{\circ} \mathrm{C}$ \\
\hline$N$ & 22 & 21 & 25 & 31 & 33 & 34 & 56 \\
\hline Head width $(\mathrm{mm} \pm \mathrm{SE})$ & $2.94 \pm 0.52$ & $2.80 \pm 0.63$ & $2.95 \pm 0.55$ & $2.98 \pm 0.60$ & $2.87 \pm 0.66$ & $2.76 \pm 0.62$ & $2.89 \pm 0.55$ \\
\hline Mean & 3.1 & 3.9 & 3.8 & 4.6 & 5.0 & 5.4 & 4.7 \\
\hline St. Dev. & 1.8 & 2.2 & 1.1 & 1.4 & 1.3 & 1.6 & 1.5 \\
\hline Min & 1.5 & 1.7 & 1.7 & 2.7 & 3.2 & 3.3 & 2.9 \\
\hline $\operatorname{Pctl}(25)$ & 1.7 & 2.3 & 3.0 & 3.7 & 3.8 & 3.9 & 3.3 \\
\hline $\operatorname{Pctl}(75)$ & 4.0 & 4.6 & 4.4 & 4.9 & 5.8 & 6.5 & 5.3 \\
\hline Max & 6.9 & 9.1 & 6.1 & 7.6 & 7.6 & 8.6 & 8.0 \\
\hline
\end{tabular}

duration $^{2}$ (Tables 2, 3). In general, CTmin decreased (improved) with both size and day of year, reflecting a combination of ontogenetic and, potentially, seasonal environmental changes. Increasing duration of exposure at either of the stressful temperatures had significant effects on CTmin. Exposure to $2^{\circ} \mathrm{C}$ had beneficial effects on thermal tolerance at short timescales of prior exposure $(30 \mathrm{~min}$ or 2 h), but these disappeared at longer prior exposure times (24 h) (Fig. $1 \mathrm{~A}, \mathrm{C})$. In contrast, exposure to $30^{\circ} \mathrm{C}$ always worsened subsequent responses to cold (Fig. 1B, D). Outputs of comparable models in which duration was modelled as a factor are qualitatively similar (Table S1, Fig. S1).

\section{DISCUSSION}

The duration and frequency of thermal extreme events are increasing in response to global warming. Although effects of frequency of previous heat or cold exposures on subsequent thermal tolerance has been often characterised (Abram et al., 2017), the effect of duration of exposure to thermal extreme events on hardening processes is less well understood. Here we provide novel data indicating that the duration of a single extreme cold challenge event can differentially impact organisms' capacity for response to future thermal challenges. Specifically, we found that short-term $(\sim 30 \mathrm{~min}-2 \mathrm{~h})$ exposure to challenging cold conditions $\left(2^{\circ} \mathrm{C}\right)$ can produce a beneficial response, which then protects individuals against future cold weather challenges. However, we find that exposure to extreme 'cold snaps' over longer periods of time (at some point $>2 \mathrm{~h}$ and $<24 \mathrm{~h}$ ) rapidly decreases the adaptive benefit of such exposures (Figs 1A, 1C, S1). These results are in accord with a Rapid Cold Hardening $(\mathrm{RCH})$ effect, which requires a short duration of recent exposure in order to be effective. This implies that, for species which depend on rapid cold hardening to protect against damage from a future thermal stressor, increased duration of the initial hardening event will have deleterious consequences.

All exposure times to an extreme heat challenge $\left(30^{\circ} \mathrm{C}\right)$ induced deleterious responses to a future cold challenge (Fig. 1B, D). These results fail to support the hypothesis that rapid hardening responses reflect a 'generalised stress response' that is transferrable to alternative thermal regimes (e.g., Burton et al., 1988). Instead, our data support the idea that stressful exposure to one extreme temperature may have detrimental effects on the ability to respond to the alternate extreme.

Our finding in this regard is similar to recent findings that increased duration of heat stress has a negative impact

Table 2. Best fit model predictors for cold tolerance (CTmin) response.

\begin{tabular}{|c|c|c|c|c|}
\hline \multirow{2}{*}{ Explanatory variables } & \multicolumn{2}{|c|}{ Coefficient } & \multirow{2}{*}{ t-value } & \multirow{2}{*}{ p-value } \\
\hline & Estimate & Standard Error & & \\
\hline Intercept & 8.27 & 0.97 & 8.49 & $<0.0001^{* * *}$ \\
\hline Head Width (mm) & -0.46 & 0.18 & -2.53 & $0.01^{\star *}$ \\
\hline Day of year (continuous) & -0.02 & 0.006 & -3.93 & $0.0001^{* * *}$ \\
\hline logDuration of thermal acclimation (h) (1) & 0.95 & 2.26 & 0.42 & 0.67 \\
\hline logDuration (2) & 7.05 & 2.16 & 3.27 & $0.001^{* *}$ \\
\hline Temperature $\left(30^{\circ} \mathrm{C}\right.$ vs $\left.2^{\circ} \mathrm{C}\right)$ & 1.22 & 0.22 & 5.51 & $0.0001^{* * *}$ \\
\hline logDuration (1) * Temperature & 3.45 & 3.29 & 1.05 & 0.30 \\
\hline logDuration (2) * Temperature & -8.93 & 3.11 & -2.88 & $0.004^{* *}$ \\
\hline
\end{tabular}

${ }^{* * *} p<0.001 ;{ }^{* *} p<0.01 ;{ }^{*} p<0.05$.

Table 3. Model comparisons.

\begin{tabular}{|c|c|c|}
\hline Included explanatory variables & $\mathrm{AICc}$ & $\triangle \mathrm{AICc}$ \\
\hline Temperature $\left(30^{\circ} \mathrm{C}\right.$ vs $\left.2^{\circ} \mathrm{C}\right){ }^{*}$ poly $(\log$ Duration, 2$)+$ head width + day of year & 823.8 & 0 \\
\hline Temperature * poly(logDuration,2) + day of year & 828.4 & 4.6 \\
\hline Temperature + logDuration + head width + day of year & 831.0 & 7.2 \\
\hline Temperature * logDuration + head width + day of year & 831.2 & 7.4 \\
\hline Temperature + head width + day of year & 834.9 & 11.1 \\
\hline Temperature * poly(logDuration,2) + head width & 837.7 & 13.9 \\
\hline Temperature + head width + duration & 838.6 & 14.8 \\
\hline Duration + head width + day of year & 848.9 & 25.1 \\
\hline
\end{tabular}



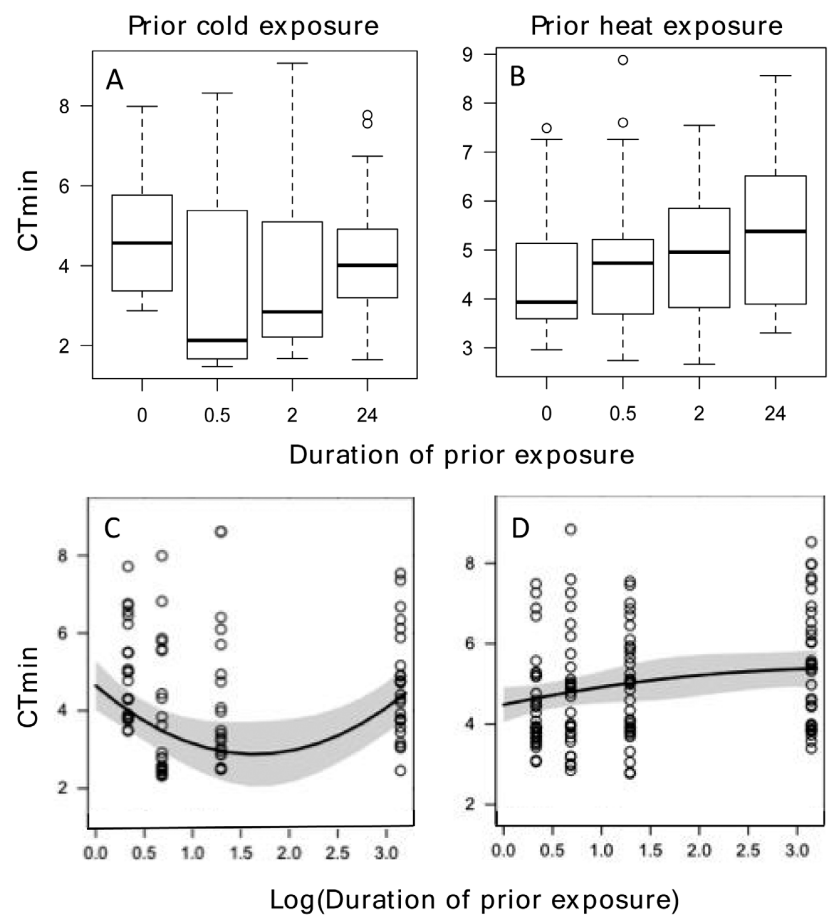

Fig. 1. Changes in $\mathrm{CTmin}\left({ }^{\circ} \mathrm{C}\right)$ as a function of the duration of a previous exposure to $2^{\circ} \mathrm{C}(\mathrm{a}, \mathrm{c})$ or $30^{\circ} \mathrm{C}(\mathrm{b}, \mathrm{d})$. Panels $\mathrm{a}, \mathrm{b}$ represent boxplots of raw CTmin values. Panels $(c, d)$ represent marginal effects of the polynomial log(Duration) term on CTmin, in models that account for effects of head width and day of year. Panels $\mathrm{C}$ $d$ were plotted using the effects package for $R$ (Fox et al., 2015). Duration of exposure in $\mathrm{a}, \mathrm{b}$ expressed in hours.

on future cold tolerance in the soil arthropod Orchesella cincta (Alemu et al., 2017). However, unlike in our study, Alemu et al. report a lack of detrimental effects of increasing cold stress duration on future cold tolerance, which may reflect differences among the studies in the degree of cold stress applied $\left(4^{\circ} \mathrm{C}\right.$ in the previous study, vs. $2^{\circ} \mathrm{C}$ in the present study) or differences in thermal capacity between freshwater and terrestrial environments. More work is needed to further investigate how the durational effects of thermal stress vary according to the degree of thermal stress applied (i.e., to examine temperature $\times$ duration interactions over a wider range of temperatures). Moreover, work on more species is needed, as previous studies suggest that species vary in the degree to which cold acclimation or hardening is induced by heat stress or vice versa (Burton et al., 1988; Hemmati et al., 2014; Bar-Ziv \& Scharf, 2018; Leonard \& Lancaster, in press).

Combined with these earlier studies, our results highlight a clear knowledge gap in understanding how interactions between intensity and duration of thermal stress can be generally predicted to affect hardening capacity. A better understanding of these effects furthermore depends on the underlying mechanisms that drive hardening and longerterm acclimation processes under different durations of heat and cold stress, as the trade-off dynamics of these alternative mechanisms are not currently widely understood.

Although not a focus of our study, our results also indicated that cold tolerance improved as body size (measured as head width) increased. In a previous Ischnura elegans thermal tolerance study, which was carried out according to similar thermal ramping protocols on larvae from the same study region, but which did not include a prior heator-cold hardening component, we found that there was no relationship between body size and thermal tolerance (Wood et al., 2019). The discrepancy between these studies suggests that body size (or developmental stage) may affect acclimation capacity, rather than directly affecting absolute thermal tolerance. Generally there is little evidence to support an improved thermal tolerance with age (Bowler $\&$ Terblanche, 2008), although some studies have shown that a rapid hardening effect declines with age (Czajka \& Lee, 1990). More work is necessary to determine how the impacts of the duration of heat or cold stress on subsequent cold tolerance differ across life stages, and how this is carried on into adult fitness in important aquatic species such as damselflies; previous work suggests that acclimation at different life stages can have different fitness costs and benefits (Ma et al., 2004; Mutamiswa et al., 2018).

Freshwater systems are particularly vulnerable to climate change and other anthropogenic changes in thermal regime (Woodward et al., 2010), including rapid changes in snowpack and runoff dynamics. Moreover, freshwater species are often represented by small metapopulations of individuals which have limited dispersal mechanisms and are therefore more sensitive to environmental thermal change (Hering et al., 2009). Therefore, investigating the implications of interspecific or inter-populational differences in effects of durational RCH responses could yield interesting results with implications for predicting future freshwater (or other) community compositions under climate change (Loeschcke \& Hoffmann, 2007; Stoks et al., 2012; Lancaster et al., 2017b). Better understanding of interspecific and interpopulational variation in durational effects of heat and cold stress on acclimation capacity of aquatic invertebrates at different life stages can contribute to better understanding of how changing durations of extreme weather events under climate change (IPCC, 2001) might impact freshwater communities and ecosystems.

ACKNOWLEDGEMENTS. We wish to thank the owners of the Midmar Stillwater Fishery for permission to sample larvae from their trout ponds. Thanks also to S. Areshi and R. Fitt for assistance in the field. This project was funded by the University of Aberdeen School of Biological Sciences, as part of their Ecology and Conservation MSc programme thesis project budget.

\section{REFERENCES}

Abram P.K., Boivin G., Moiroux J. \& Brodeur J. 2017: Behavioural effects of temperature on ectothermic animals: unifying thermal physiology and behavioural plasticity. - Biol. Rev. 92: 1859-1876.

Alemu T., Alemneh T., Pertoldi C., Ambelu A. \& Bahrndorff S. 2017: Costs and benefits of heat and cold hardening in a soil arthropod. - Biol. J. Linn. Soc. 122: 765-773.

Baker H.S., Millar R.J., Karoly D.J., Beyerle U., Guillod B.P., Mitchell D., Shiogama H., Sparrow S., Woollings T. \& Allen M.R. 2018: Higher $\mathrm{CO}_{2}$ concentrations increase extreme event risk in a $1.5^{\circ} \mathrm{C}$ world. - Nature Clim. Change 8: 604-608. 
BAR-ZIV M.A. \& SCHARF I. 2018: Thermal acclimation is not induced by habitat-of-origin, maintenance temperature, or acute exposure to low or high temperatures in a pit-building wormlion (Vermileo sp.). - J. Therm. Biol. 74: 181-186.

Bouton N., Iserbyt A. \& Van Gossum H. 2011: Thermal plasticity in life-history traits in the polymorphic blue-tailed damselfly, Ischnura elegans: No differences between female morphs. - J. Insect Sci. 11: 112, 11 pp.

BOWLER K. \& Terblanche J.S. 2008: Insect thermal tolerance: what is the role of ontogeny, ageing and senescence? - Biol. Rev. 83: 339-355.

Buckley L.B. \& Huey R.B. 2016: Temperature extremes: geographic patterns, recent changes, and implications for organismal vulnerabilities. - Global Change Biol. 22: 3829-3842.

Burnham K.P. \& Anderson D.R. 2002: Model Selection and Multimodel Inference: A Practical Information-Theoretic Approach. Springer, New York, 488 pp.

Burton V., Mitchell H.K., Young P. \& Petersen N.S. 1988: Heat shock protection against cold stress of Drosophila melanogaster. - Mol. Cell. Biol. 8: 3550-3552.

Bybee S., Córdoba-Aguilar A., Duryea M.C., Futahashi R., Hansson B., Lorenzo-Carballa M.O., Schilder R., Stoks R., Suvorov A., Svensson E.I. ET AL. 2016: Odonata (dragonflies and damselflies) as a bridge between ecology and evolutionary genomics. - Front. Zool. 13: 46, 20 pp.

Снам S. 2009: Field Guide to the Larvae and Exuviae of British Dragonflies. Vol. 2: Zygoptera. British Dragonfly Society, Peterborough, $152 \mathrm{pp}$.

Chanthy P., Martin R.J., Gunning R.V. \& Andrew N. 2012: The effects of thermal acclimation on lethal temperatures and critical thermal limits in the green vegetable bug, Nezara viridula (L.) (Hemiptera: Pentatomidae). — Front. Physiol. 3: 465, 8 pp.

Colinet H. \& Hoffmann A.A. 2012: Comparing phenotypic effects and molecular correlates of developmental, gradual and rapid cold acclimation responses in Drosophila melanogaster. - Funct. Ecol. 26: 84-93.

Colinet H., Lee S.F. \& Hoffmann A. 2010: Temporal expression of heat shock genes during cold stress and recovery from chill coma in adult Drosophila melanogaster. - FEBS J. 277: 174-185.

Córdoba-Aguilar A. 2008: Dragonflies and Damselflies: Model Organisms for Ecological and Evolutionary Research. Oxford University Press, Oxford, $304 \mathrm{pp}$.

CzaJKa M.C. \& LeE R.E. 1990: A rapid cold-hardening response protecting against cold shock injury in Drosophila melanogaster. - J. Exp. Biol. 148: 245-254.

Deutsch C.A., Tewksbury J.J., Huey R.B., Sheldon K.S., Ghalambor C.K., HaAk D.C. \& Martin P.R. 2008: Impacts of climate warming on terrestrial ectotherms across latitude. Proc. Nat. Acad. Sci. 105: 6668-6672.

Dudaniec R.Y., Yong C.J., Lancaster L.T., Svensson E.I. \& HAnsson B. 2018: Signatures of local adaptation along environmental gradients in a range-expanding damselfly (Ischnura elegans). - Mol. Ecol 27: 2576-2593.

EASAC 2013: Trends in Extreme Weather Events in Europe: Implications for National and European Union Adaptation Strategies. EASAC Policy Report 22. European Academies Science Advisory Council, London, URL: https://easac.eu/fileadmin/ PDF_s/reports_statements/Extreme_Weather/EASAC_report Extreme_Weather_in_Europe_Nov13.pdf

ENRIQUez T. \& COLINET H. 2019: Cold acclimation triggers major transcriptional changes in Drosophila suzukii. — BMC Genom. 20: $413,17 \mathrm{pp}$.
FITT R.N.L. \& LANCASTER L.T. 2017: Range shifting species reduce phylogenetic diversity in high latitude communities via competition. - J. Anim. Ecol. 86: 543-555.

Fitt R.N.L., Palmer S., Hand C., Travis J.M.J. \& Lancaster L.T. 2019: Towards an interactive, process-based approach to understanding range shifts: developmental and environmental dependencies matter. - Ecography 42: 201-210.

Fox J. 2003: Effect displays in R for generalised linear models. J. Stat. Softw. 8(15), 27 pp.

Fox J. \& Weisberg S. 2018: An R Companion to Applied Regression. SAGE, Thousand Oaks, CA, 608 pp.

Frich P., Alexander L.V., Della-Marta P.M., Gleason B., HayLock M., Tank A.M.G.K. \& Peterson T. 2002: Observed coherent changes in climatic extremes during the second half of the twentieth century. - Climate Res. 19: 193-212.

Gilman S.E., Urban M.C., Tewksbury J., Gilchrist G.W. \& Holt R.D. 2010: A framework for community interactions under climate change. - Trends Ecol. Evol. 25: 325-331.

Gotcha N., Terblanche J.S. \& Nyamukondiwa C. 2018: Plasticity and cross-tolerance to heterogeneous environments: divergent stress responses co-evolved in an African fruit fly. $-J$. Evol. Biol. 31: 98-110.

Hemmati C., Moharramipour S. \& Talebi A.A. 2014: Effects of cold acclimation, cooling rate and heat stress on cold tolerance of the potato tuber moth Phthorimaea operculella (Lepidoptera: Gelechiidae). — Eur. J. Entomol 111: 487-494.

Hering D., Schmidt-Kloiber A., Murphy J., Lücke S., ZamoraMuñoz C., López-Rodríguez J.L., Huber T. \& GraF W. 2009: Potential impact of climate change on aquatic insects: A sensitivity analysis for European caddisflies (Trichoptera) based on distribution patterns and ecological preferences. - Aquat. Sci. 71: 3-14.

Hickling R., Roy D.B., Hill J.K., Fox R. \& Thomas C.D. 2006: The distributions of a wide range of taxonomic groups are expanding polewards. - Global Change Biol. 12: 450-455.

IPCC 2001: Third Assessment Report of the Intergovernmental Panel on Climate Change IPCC (WG I \& II). Cambridge Univ. Press, Cambridge.

Jackson F.L., Fryer R.J., Hannah D.M., Millar C.P. \& Malcolm I.A. 2018: A spatio-temporal statistical model of maximum daily river temperatures to inform the management of Scotland's Atlantic salmon rivers under climate change. - Science Total Environ. 612: 1543-1558.

Kendon M., McCarthy M., Jevrejeva S., Matthews A. \& LegG T. 2018: State of the UK climate 2017. - Int. J. Climatol. 38: $1-35$.

Kennedy JR W.J. \& Gentle J.E. 1980: Statistical Computing. Marcel Dekker, New York, Basel, 591 pp.

Knapp M., Vernon P. \& Renault D. 2018: Studies on chill coma recovery in the ladybird, Harmonia axyridis: Ontogenetic profile, effect of repeated cold exposures, and capacity to predict winter survival. - J. Therm. Biol. 74: 275-280.

Kodra E., Steinhaeuser K. \& Ganguly A.R. 2011: Persisting cold extremes under 21 st-century warming scenarios. - Geophys. Res. Lett. 38: L08705, 5 pp.

Krokowski J.T. 2007: Changes in the trophic state and phytoplankton composition and abundance in Loch Lomond, Scotland, UK. - Oceanol. Hydrobiol. Stud. 36: 17-34.

Lancaster L.T., Dudaniec R.Y., Hansson B. \& Svensson E.I. 2015: Latitudinal shift in thermal niche breadth results from thermal release during a climate-mediated range expansion. J. Biogeogr. 42: 1953-1963.

Lancaster L.T., Dudaniec R.Y., Chauhan P., Wellenreuther M., Svensson E.I. \& Hansson B. 2016: Gene expression under 
thermal stress varies across a geographical range expansion front. - Mol. Ecol. 25: 1141-1156.

Lancaster L.T., Dudaniec R.Y., Hansson B. \& Svensson E.I. 2017a: Do group dynamics affect colour morph clines during a range shift? - J. Evol. Biol. 30: 728-737.

Lancaster L.T., Morrison G. \& Fitt R.N. 2017b: Life history trade-offs, the intensity of competition, and coexistence in novel and evolving communities under climate change. Phil. Trans. R. Soc. (B) 372: 20160046, 10 pp.

Lee R.E. JR., Chen C.P. \& Denlinger D.L. 1987: A rapid coldhardening process in insects. - Science 238: 1415-1417.

LEONARD A. \& LANCASTER L.T. in press: Maladaptive plasticity facilitates evolution of thermal tolerance during an experimental range shift. - BMC Evol. Biol. DOI: 10.1186/s12862-020$1589-7$.

Loeschere V. \& Hoffmann A.A. 2007: Consequences of heat hardening on a field fitness component in Drosophila depend on environmental temperature. - Am. Nat. 169: 175-183.

Ma C.-S., Hau B. \& Poenling H.-M. 2004: The effect of heat stress on the survival of the rose grain aphid, Metopolophium dirhodum (Hemiptera: Aphididae). — Eur. J. Entomol. 101: 327-332.

Macdonald S.S., Rako L., Batterham P. \& Hoffmann A.A. 2004 Dissecting chill coma recovery as a measure of cold resistance: evidence for a biphasic response in Drosophila melanogaster. - J. Insect Physiol. 50: 695-700.

MacMillan H.A., Knee J.M., Dennis A.B., Udaka H., Marshall K.E., Merritt T.J.S. \& Sinclair B.J. 2016: Cold acclimation wholly reorganizes the Drosophila melanogaster transcriptome and metabolome. - Sci. Rep. 6: 28999, 14 pp.

Manenti T., Sørensen J.G. \& Loeschcke V. 2017: Environmental heterogeneity does not affect levels of phenotypic plasticity in natural populations of three Drosophila species. - Ecol. Evol. 7: 2716-2724.

Marais E., Terblanche J.S. \& Chown S.L. 2009: Life stage-related differences in hardening and acclimation of thermal tolerance traits in the kelp fly, Paractora dreuxi (Diptera, Helcomyzidae). - J. Insect Physiol. 55: 336-343.

Mazerolle M.J. 2016: AICcmodavg: Model Selection and Multimodel Inference Based on (Q) AIC (c). R Package Ver. 2.0-3. URL: https://cran. r-project. org/package= AICcmodavg.

McGrath M. 2018: Weather: UK Experiencing Hotter Days and 'Tropical Nights'- Met Office. BBC News, URL: https://www. bbc.co.uk/news/science-environment-46064266.

Meenl G.A. \& Tebaldi C. 2004: More intense, more frequent, and longer lasting heat waves in the 21 st century. - Science 305: 994-997.

Met Office N.C.I.C. 2018: State of the UK Climate 2017: Supplementary Report on Climate Extremes. URL: https://www. metoffice.gov.uk/binaries/content/assets/metofficegovuk/pdf/ weather/learn-about/uk-past-events/state-of-uk-climate/soc supplement-002.pdf

Mutamiswa R., MacheKano H., ChidawanyiKa F. \& NyamuKondWA C. 2018: Life-stage related responses to combined effects of acclimation temperature and humidity on the thermal tolerance of Chilo partellus (Swinhoe) (Lepidoptera: Crambidae). $-J$. Therm. Biol. 79: 85-94.

Nyamukondiwa C. \& Terblanche J.S. 2010: Within-generation variation of critical thermal limits in adult Mediterranean and Natal fruit flies Ceratitis capitata and Ceratitis rosa: thermal history affects short-term responses to temperature. - Physiol. Entomol. 35: 255-264.

Nyamukondiwa C., Chidawanyika F., Machekano H., Mutamiswa R., Sands B., Mgidiswa N. \& Wall R. 2018: Climate variability differentially impacts thermal fitness traits in three co- prophagic beetle species. — PLOS ONE 13(6): e0198610, 13 pp.

PARMESAN C. 2006: Ecological and evolutionary responses to recent climate change. - Annu. Rev. Ecol. Evol. Syst. 37: 637669.

Rajamohan A. \& Sinclair B.J. 2009: Hardening trumps acclimation in improving cold tolerance of Drosophila melanogaster larvae. - Physiol. Entomol. 34: 217-223.

RAKo L. \& HofFManN A.A. 2006: Complexity of the cold acclimation response in Drosophila melanogaster. - J. Insect Physiol. 52: 94-104.

Sánchez-Guillén R.A., Córdoba-Aguilar A., Hansson B., Ott J. \& WellenREuther M. 2016: Evolutionary consequences of climate-induced range shifts in insects. - Biol. Rev. 91: 10501064.

Semsar-Kazerouni M. \& Verberk W.C.E.P. 2018: It's about time: Linkages between heat tolerance, thermal acclimation and metabolic rate at different temporal scales in the freshwater amphipod Gammarus fossarum Koch, 1836. - J. Therm. Biol. 75: 31-37.

Sgro C.M., Terblanche J.S. \& Hoffmann A.A. 2016: What can plasticity contribute to insect responses to climate change? Annu. Rev. Entomol. 61: 433-451.

Sørensen J.G., Kristensen T.N. \& Loeschcke V. 2003: The evolutionary and ecological role of heat shock proteins. - Ecol. Lett. 6: 1025-1037.

Stoks R. \& De Block M. 2011: Rapid growth reduces cold resistance: evidence from latitudinal variation in growth rate, cold resistance and stress proteins. - PLOS ONE 6(2): e16935, 6 pp.

Stoks R., Swillen I. \& De Block M. 2012: Behaviour and physiology shape the growth accelerations associated with predation risk, high temperatures and southern latitudes in Ischnura damselfly larvae. - J. Anim. Ecol. 81: 1034-1040.

Terblanche J.S., Deere J.A., Clusella-Trullas S., Janion C. \& Chown S.L. 2007: Critical thermal limits depend on methodological context. - Proc. R. Soc. Lond. (B) 274: 2935-2943.

Waagner D., Holmstrup M., Bayley M. \& Sørensen J.G. 2013: Induced cold-tolerance mechanisms depend on duration of acclimation in the chill-sensitive Folsomia candida (Collembola). - J. Exp. Biol. 216: 1991-2000.

WicкHAм H. 2016: ggplot2: Elegant Graphics for Data Analysis. Springer, New York, URL: http://ggplot2.org

Wood C., Fitt R.N.L. \& Lancaster L.T. 2019: Evolving social dynamics prime thermal tolerance during a poleward range shift. — Biol. J. Linn. Soc. 126: 574-586.

Woodward G., Perkins D.M. \& Brown L.E. 2010: Climate change and freshwater ecosystems: impacts across multiple levels of organization. - Phil. Trans. R. Soc. (B) 365: 20932106.

ZuUR A.F., Leno E.N. \& Elphick C.S. 2010: A protocol for data exploration to avoid common statistical problems. - Meth. Ecol. Evol. 1: 3-14.

Received June 19, 2019; revised and accepted February 5, 2020 Published online February 17, 2020

Supplementary analysis. Modelling the duration of thermal exposure as a factor reveals congruent results to analyses where duration is treated as a continuous variable, see Table S1 and Fig. $\mathrm{S} 1$ below. 
Table S1. Pairwise, interactive comparisons of temperature and durations where both duration and temperature are modelled as factors, where significant effects are highlighted at a Bonferroni-corrected alpha of 0.016 .

\begin{tabular}{|c|c|c|c|c|}
\hline Variable & Effect & S.E. & $\mathrm{t}$ & $\mathrm{P}$ \\
\hline Duration (0 vs. $0.5 \mathrm{~h})$ & -1.63 & 0.45 & -3.58 & 0.0004 \\
\hline Duration (0 vs. 2 h) & -1.22 & 0.47 & -2.6 & 0.01 \\
\hline Duration (0 vs. 24 h) & -0.49 & 0.44 & -1.11 & 0.27 \\
\hline Duration (0.5 vs. 2 h) & 0.41 & 0.47 & 0.86 & 0.39 \\
\hline Duration (0.5 vs. 24 h) & 1.14 & 0.45 & 2.54 & 0.01 \\
\hline Duration (2 vs. 24 h) & 0.73 & 0.46 & 1.58 & 0.11 \\
\hline Duration $(0$ vs. $0.5 \mathrm{~h}) \times$ Temperature $\left(30\right.$ vs. $\left.0^{\circ} \mathrm{C}\right)$ & 1.97 & 0.6 & 3.3 & 0.001 \\
\hline Duration $(0$ vs. $2 \mathrm{~h}) \times$ Temperature $\left(30\right.$ vs. $\left.0^{\circ} \mathrm{C}\right)$ & 1.73 & 0.6 & 2.86 & 0.005 \\
\hline Duration ( 0 vs. $24 \mathrm{~h}) \times$ Temperature $\left(30\right.$ vs. $\left.0^{\circ} \mathrm{C}\right)$ & 1.42 & 0.58 & 2.45 & 0.01 \\
\hline Duration $(0.5$ vs. $2 \mathrm{~h}) \times$ Temperature $\left(30\right.$ vs. $\left.0^{\circ} \mathrm{C}\right)$ & -0.24 & 0.61 & -0.4 & 0.69 \\
\hline Duration $(0.5$ vs. $24 \mathrm{~h}) \times$ Temperature $\left(30\right.$ vs. $\left.0^{\circ} \mathrm{C}\right)$ & -0.55 & 0.59 & -0.94 & 0.35 \\
\hline Duration $\left(2\right.$ vs. 24 h) $\times$ Temperature $\left(30\right.$ vs. $\left.0^{\circ} \mathrm{C}\right)$ & -0.31 & 0.6 & -0.52 & 0.6 \\
\hline
\end{tabular}

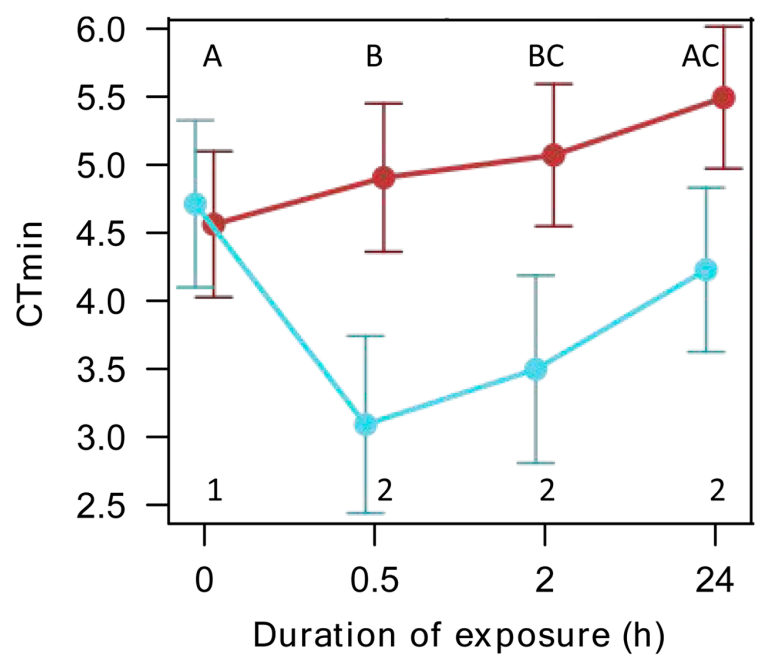

Fig. S1. Effects of duration $(\mathrm{h}) \times$ temperature $\left(30^{\circ} \mathrm{C}=\right.$ red, $2^{\circ} \mathrm{C}=$ blue) of prior exposure on subsequent $\mathrm{CTmin}\left({ }^{\circ} \mathrm{C}\right)$. Differing letters along the top indicate durations which differ in their effects on CTmin within each treatment (letters along top for the $30^{\circ} \mathrm{C}$ treatment, letters along the bottom for the $2^{\circ} \mathrm{C}$ treatment). Asterisks indicate the time points at which the treatments differ in their effects on CTmin. 